University of Rhode Island

DigitalCommons@URI

2018

\title{
Treating Outer Space Like a Place: A Case for Rejecting Other Domain Analogies
}

Elizabeth Mendenhall

University of Rhode Island, mendenhall@uri.edu

Follow this and additional works at: https://digitalcommons.uri.edu/maf_facpubs

The University of Rhode Island Faculty have made this article openly available.

Please let us know how Open Access to this research benefits you.

This is a pre-publication author manuscript of the final, published article.

Terms of Use

This article is made available under the terms and conditions applicable towards Open Access

Policy Articles, as set forth in our Terms of Use.

Citation/Publisher Attribution

Elizabeth Mendenhall (2018) Treating Outer Space Like a Place: A Case for Rejecting Other Domain Analogies, Astropolitics, 16:2, 97-118, DOI: 10.1080/14777622.2018.1484650 Available at:

http://dx.doi.org/10.1080/14777622.2018.1484650

This Article is brought to you for free and open access by the Marine Affairs at DigitalCommons@URI. It has been accepted for inclusion in Marine Affairs Faculty Publications by an authorized administrator of DigitalCommons@URI.For more information, please contact digitalcommons-group@uri.edu. 
Treating Outer Space Like a Place:

A Case for Rejecting Other Domain Analogies

\author{
Elizabeth Mendenhall \\ Assistant Professor \\ University of Rhode Island
}

\begin{abstract}
This article considers the use of analogies in building and reforming the outer space governance regime. It begins by reviewing the historical use of comparisons between the 'target' domain of outer space and the 'source' domains of airspace, the seabed, the high seas, and Antarctica. After describing how these analogies shaped the Outer Space Treaty, a survey of contemporary literature demonstrates that analogies continue to be used to structure thinking about outer space activities. The central argument of the article is that analogies are a misleading foundation for constructing a governance regime in outer space. They overlook essential and distinct features of outer space, and misguide the actions of policymakers by influencing interest formation and problem definition. The second section identifies six major features of the outer space environment that are concealed by other-domain analogies, and describes their impact on the requirements for effective governance. The final section presents an alternative, non-analogic representation of outer space as a place, and draws some general conclusions about its implications for space governance.
\end{abstract}

The suddenness of the Space Age created a new set of challenges for international law, and the rules to manage space activity were created before those challenges were fully comprehended. Governance preceded understanding. At the opening of negotiations over the Outer Space Treaty (OST), "most governments had little conception of space or space activity," even though Sputnik had entered Earth orbital space almost a decade prior. ${ }^{1}$ Before specific rules and norms for space activities could be agreed upon, diplomats first had to establish a shared 'locational classification' for outer space. Classifying outer space as an arena of activity was necessary to allow participating governments to define the situation, identify their interests, and determine their identities as space actors. Only then could they pursue the creation of a treaty to manage outer space in the interests of each and all. But rather than waiting for a full appreciation and understanding of this new domain of activity, key actors relied on analogies with other international domains - the ocean, airspace, and Antarctica - to classify outer space. In doing so, they misrepresented the problems of collective use of outer space, and misidentified their own interests. The result is a dysfunctional outer space regime that persists today, unable to resolve key questions and confront emerging issues. This article argues that analogies between space and other planetary domains, which still enjoy significant circulation among the space community, represent the wrong approach to outer space governance, and risk repeating the mistakes of past regime building.

Although the use of domain analogies for outer space has been studied in great detail, existing treatments accept and even embrace this strategy as useful or inevitable. ${ }^{2}$ Most notable is M.J. Peterson's work on the outer space regime, including a 1997 article in International 
Organization and her 2005 book International Regimes for the Final Frontier. ${ }^{3}$ Peterson acknowledges that analogies can be judged based on how well they represent the actual domain; an analogy can have more or less 'fit' with the material realities of outer space. But her historical recounting demonstrates in detail that movement between analogies was mostly (if not entirely) driven by superior political 'fit' with the purposes and interests of dominant actors. ${ }^{4}$ This can be understood as a case of 'seeing what one wants to see.' When shifts in power among states and interest within states occur, a new analogy with better 'fit' is adopted. Peterson under-plays the point that the 'fit' of any given analogy with material reality changes too, as scientific understanding comes into focus. The more we understand about actual outer space, the better we can identify what an analogy fails to capture. In neglecting the relationship between analogies and material reality, Peterson overlooks the way that scientific knowledge accumulation progressively undermines the 'fit' of any given analogy with the material context of outer space itself. Indeed, the increasingly accurate scientific image of outer space represents an external standard with which other domain analogies can be usefully evaluated.

Contemporary International Relations has been moving in the other direction. Instead of harnessing new scientific knowledge about planetary domains to evaluate the utility of social and political representations, scholars have embraced the idea that all images of planetary space scientific or otherwise - are social constructions. This approach to outer space is demonstrated by Jason Beery's 2016 article in Political Geography. ${ }^{5}$ Beery explains the construction of outer space as a 'global commons' using a "production of nature approach." He explicitly rejects the existence of a "fixed, pre-given, and separate" natural world in favor of an outer space that is "socially produced" by inherently political scientific "framings" that serve the interests of dominant actors and reinforce inequality. ${ }^{6}$ Under this view, the analog and the 'target' of the analogy have equal ontological status; they are both constructed, neither is more 'real' than the other. Outer space for Beery is defined by its political geography of non-appropriation, free access, and collective benefit. He rejects the notion of an objective, material domain, thereby relinquishing any scientific standard for evaluating the accuracy of an analogy as a representation of the outer space domain.

This article adopts an alternative approach, one that emphasizes the special role of scientific knowledge in producing a useable and useful 'locational classification.' Although this may seem like a basic insight, the vast literature on the history of space access underemphasizes the influence of geography and geophysics, and what we know about them and when, on space activities. ${ }^{7}$ This article addresses two basic questions: what do analogies overlook or downplay about the space domain, and how has their use impacted governance in outer space? I argue that a scientific image of the outer space domain highlights its unique material features as a place, in contrast to other-domain analogies (ocean, airspace, Antarctica), which tend to elide and obscure important features of the outer space environment. This scientific image - which is progressively updated in pursuit of an accurate representative of the objective material world - is more useful for collective governance, because outer space itself places constraints on what humans can do, how they can do it, and the consequences. In other words, the material features of space, interacting with technologies of access, shape the practices, interests, and problems that motivate the formation and operation of the outer space regime. When the space environment is misunderstood and mischaracterized, so are the interests of diverse actors, and the problems caused by shared use and free access. The stakes of accurate representation are regime effectiveness: when interests and problems are misconceived at the time of regime formation, the 
result is international laws that inadequately serve the individual space user and larger space community.

The first section surveys the history of applying other-domain analogies to the international governance of outer space. During the first decades of regime formation, space actors and international lawyers utilized a rotating set of analogies to import pre-existing legal principles, norms, and rules. Despite decades of scientific activity in outer space, these analogies are still relied upon for understanding what outer space is like today. The second section outlines several ways that the use of analogies shaped the outer space regime in unproductive, and even counterproductive, ways. International law of outer space has persisted largely unchanged since the 1960s and 1970s, yet space science and science activities have continued to increase and advance. This makes the mismatch between space law and space itself increasingly visible. The third section connects the scientific, non-analogic, approach to 'locational classification' with the formation of governance principles and norms to demonstrate how abandoning the use of analogies can bring clarity to the agenda for reforming and augmenting contemporary outer space governance.

Analogies with Outer Space

During the first decades of the Space Age, reliance on other domain analogies prevailed in the United Nations Committee on the Peaceful Uses of Outer Space (COPUOS). Until the mid-1970s, COPUOS was the "single most important source of international law relating to space activities." 8 The committee is divided into a Scientific and Technical subcommittee and a Legal subcommittee. The Scientific and Technical subcommittee was charged with developing shared knowledge about space and the potentials of space activity, while the Legal subcommittee drafted multilateral agreements for collective governance of outer space. The Scientific and Technical subcommittee would help define and shape the agenda of the Legal subcommittee, by identifying existing and emerging international problems in space. But the Legal subcommittee got ahead of its counterpart, fashioning agreements before the work of the Scientific and Technical subcommittee could really inform their content. The urgency and high stakes of Cold War politics, and the uncertainty about who would achieve space milestones first, drove the Soviet Union and United States - the two early space powers - to actively pursue negotiated agreements for fear that events, activities, and the precedents they set would take the bipolar rivalry in dangerous or disadvantageous directions.

This urgency empowered the Legal subcommittee to make key decisions about the principles, norms, and rules of outer space law. Instead of space experts, it was international lawyers - highly trained in analogical reasoning - that had the largest influence on early regime formation out of COPUOS. ${ }^{9}$ Peterson describes how the use of analogies facilitated "direct transfers of ideas" from Earth-bound international agreements to the new space regime. ${ }^{10}$ The use of other-domain ideas obtained a kind of momentum early on, and persisted through inertia. By the time COPUOS activity slowed down in the late 1970s and 1980s, the proportion of technical experts on the committee had decreased in favor of diplomatic generalists, who because of their lack of familiarity with the specific features of outer space are more likely to rely on cognitive shortcuts like analogy. The overall result was a space regime founded on earthbound analogies. ${ }^{11}$ Three such analogies will be considered: airspace, the ocean, and Antarctica. 


\section{Airspace}

The analogy between airspace and outer space had initial intuitive appeal, because of their shared ascendant position and the notion that vehicles in either are 'flying.' The term 'aerospace' reflects the belief that space is a continuation of airspace, and some legal scholars at the beginning of the Space Age proposed that the legal regime for airspace was an important precedent for outer space. Problems associated with injury, damage, and loss from space vehicles have been described as "identically the same...in international air law." 12 But the airspace analogy quickly fell out of favor, and virtually no one forwarded it after 1961. Peterson argues that the strongest explanation - a materialist explanation - is the "poorer fit with what was known about space," particularly the basic nature of orbital mechanics. ${ }^{13}$ The air analogy implied that outer space should be divided into national segments treated as sovereign territories, but "lawyers and governments alike had trouble conceiving how a country might claim sovereignty over a vacuum whose location was constantly shifting." 14 Of course, it was not the vacuum itself with a shifting location. Objects in any orbital trajectory, even those that appear stationary relatively to a point on Earth, are constantly moving through different points in space. The airspace analogy was rejected for the same basic reason physical partitioning of outer space was abandoned: sovereign territory makes little sense in the orbital space environment.

\section{Ocean}

The analogy that most dominated the early and middle periods of space activity compared outer space to the ocean. ${ }^{15}$ There are two different versions of this analogy: a comparison of space itself with the high seas, and a comparison of celestial bodies (like the Moon) with the seabed. The idea that outer space is like the high seas had intuitive appeal, because both are vast and fluid, and contain areas of solid material. The comparison was also readily available given the on-going negotiations over the Law of the Sea during the 1960s, $1970 \mathrm{~s}$, and 1980s. The version of this analogy with the most uptake in the international community asserts that outer space is like the high seas, and should therefore be treated as an open access area that can be used by everyone, but not appropriated by anyone: a res communis. On the high seas, states are 'flag states,' responsible for enforcing regulations on their own nationals, and especially on ships registered in their state. The view that outer space was like high seas was used to define the political-geographical border between outer space (understood as high seas) and airspace (understood as territorial seas). ${ }^{16}$ As a result of this analogy, a significant amount of ocean governance precedent was transferred to the outer space regime, especially obligations associated with ships and crews, such as those regarding rescue, piracy, navigational aids, liability, and registration. ${ }^{17}$ The basic regime regarding spaceflight is modeled on the idea of high seas' freedoms (of access) and flag state jurisdiction.

The high seas analogy also implied a parallel between islands in the ocean, and 'islands in space. ${ }^{18}$ While islands in the ocean were historically territorialized, international lawyers and diplomats did not want celestial bodies to be characterized as res nullius and be subject to state appropriation. Neither side of the 'space race' knew who would get to such places first, so both preferred a principle of non-appropriation of celestial bodies. Because islands in the Earth's ocean were treated as res nullius and therefore subject to appropriation, the argument that moons and asteroids should not be understood this way required an analogy shift. During the late 1970s, in negotiations for the Moon Agreement, celestial bodies were compared to the non-coastal seabed which had been declared the 'common heritage of mankind' in the late 1960s and early 1970s. This public ownership model reserved the mineral resources of the deep seabed for the 
international community as a whole and included a distributional mandate. Indeed, the Moon Agreement has many institutional features - principles, norms, and rules - drawn directly from the provisions for the International Seabed Authority. But the Moon Agreement is ineffective, having never been ratified by any major space actor. The outer space regime largely embeds another analogy to address the status of celestial bodies. Instead of being treated like islands (res nullius) or the seabed (res publica), the outer space regime treats celestial bodies as akin to Antarctica.

\section{Antarctica}

The analogy between outer space and Antarctica became salient towards the end of negotiations over OST, and "supplied solutions to a number of practical problems" for space users. ${ }^{19}$ Comparisons between the southern continent and outer space already existed in the public consciousness, as both places were understood as 'last frontiers' and formidable natural obstacles to potentially lucrative exploration and development. James Spiller describes how the outer space/Antarctica analogy was activated and made prominent as a strategic government narrative, picked up by the popular media, and designed to "garner public support for these strategic national initiatives and, more generally, for American Cold War internationalism."20 The analogy with Antarctica was not chosen for its material accuracy, but because the connection was "culturally salient," and a way to tie past American mastery of terrestrial frontiers to Cold War activities. ${ }^{21}$ Comparing outer space and Antarctica served strategic national interests: both programs were motivated by national defense, military advantage, and international prestige. Both represented grand challenges that could prove the power and capability of a superpower and its political-economic system. ${ }^{22}$

The legacy of this analogy is apparent in both domestic and international institutions. Spiller identifies "organizational similarities" between NASA and the U.S. Antarctica Program, and notes that diplomats in each area continued to draw "energy and lessons" from one another for many decades. ${ }^{23}$ On the international level, the Antarctic Treaty System - which came into being in 1959 - was understood as a test for principles and norms to be applied to outer space. ${ }^{24}$ The Antarctic Treaty placed competing territorial claims in abeyance and reserved the continent for peaceful, and especially scientific, purposes. It demonstrated a path for avoiding militarized superpower conflict in a new planetary domain. Some scholars of outer space argue that the Antarctic Treaty System served as the analogical "base model" for the outer space regime. ${ }^{25}$ Like the Antarctic Treaty, the OST replaces the assumption of res nullius with a principle of res communis, but with states retaining control over national objects and people. ${ }^{26}$ And like the Antarctica Treaty, the OST also enshrines a right of peaceful scientific research and prohibits weapons of mass destruction in orbit and on celestial bodies.

Comparison between outer space and Antarctica was not limited to historical, political, and legal dimensions. Even though the analogy was not chosen for its material accuracy, Spiller's account illustrates how a material comparison was treated as valid and useful. In the same month that OST became open for signature (January 1967), NASA officials visited Antarctica in order to learn about maintaining human exploration in a harsh environment, on one of the two remaining 'last frontiers'. Because of its environment, Antarctica was considered an "ideal testing ground" for equipment, infrastructure, and logistics that might be used in outer space. ${ }^{27}$ It was assumed that biological life in general, and human life in particular, face the same types of challenges in Antarctica and outer space. This analogy extended to the relationship between the geophysical environment and technological capabilities; nuclear propulsion was 
understood to be equally revolutionary for icebreaker ships and rockets to space, such that access to either would be cheap and easy. ${ }^{28}$

It was not the discovery of material differences that caused that comparison between outer space and Antarctica to fade. Spiller argues that the analogy broke down during the 1970s because the government relied on two different explanations for why lofty expectations for exploitation of each remained unfulfilled. The common narrative about a resource bonanza needed to be replaced. While the framing of Antarctica shifted to protection of an environmentally fragile region, the framing of outer space remained focused on economic advantage, but reoriented to more Earth-bound benefits like jobs, spinoff technologies, and the uses of satellite monitoring data. ${ }^{29}$ While Antarctica needed to be kept pollution-free, outer space was not understood to be at risk from pollution. Spiller explains that the main reason that the Antarctic analogy did not cause a "paradigm shift" in thinking about space was that there were "too many interests committed to a more robust program and too many people attached to the romantic idea of the space frontier." ${ }^{30}$ In other words, the analogy was prominent when it served strategic national interests, and abandoned when it did not. When it was employed, it was assumed to extend to both material and political aspects of outer space.

Analogies to the outer space domain are still widely deployed in the speeches of policymakers, arguments of diplomats, reports of analysts, and studies of scholars. Indeed, in 2014 the journal Astropolitics published a special issue on the 'Power of Analogies for Advancing Space Scientific Knowledge.' 31 Many such analogies are fined-grained, in that they compare a very narrow aspect of the history of space access to another type of earthbound activity. The special issue of Astropolitics purportedly focuses on analogies that relate to spaceflight. ${ }^{32}$ Some of these articles introduce new analogies, such as a comparison between spaceflight and mountaineering, and between the space program and the railroads. ${ }^{33}$ Others unpack broad historical analogies, such as between the American western frontier and the space program and Antarctica and outer space as places. ${ }^{34}$ Material comparisons emerge throughout, such as the reliance on Earth geology as training for lunar geology, and the extrapolations from Earth biology to astrobiology. ${ }^{35}$ The position articulated here does not reject such analogizing wholesale; comparisons between government programs, popular reactions, funding models, and other social and political realities can be illuminating. But broad material comparisons are misleading: outer space is not a place like any other. Yet wholesale analogies between the outer space environment and the ocean, Antarctica, and airspace still pervade contemporary thinking. These comparisons appear fundamentally plausible and helpful, because each place is (or was) coded as a frontier and a global commons. But the particular analogy chosen still depends on what aspect of outer space activities is focused on, and what interests and goals are represented by the author. A cursory review of the outer space literature reveals as much.

Comparisons with airspace and the high seas are especially common in the security realm, and tend to structure approaches to power projection and war fighting in space. ${ }^{36}$ The high seas analogy has been used to argue in favor of U.S. policing activities, Chinese strategies related to 'space control,' and the legitimacy of space-based power and conflict more generally. ${ }^{37}$ References to the Law of the Sea Convention are especially common, and have been used to justify private asteroid mining, to propose a legal model for utilization of lunar resources, and to argue for the creation of national exclusion zones. ${ }^{38}$ The Antarctic analogy is forwarded by Spiller as a way to bring space activity 'back to Earth' and abandon more visionary frontierism. ${ }^{39}$ Even the basic airspace analogy persists - the contrast between physical atmosphere and abstract airspace has been used to explain how a res communis regime can coexist with 
sovereign territory in outer space. ${ }^{40}$ Each analogy is used to argue in favor of a particular political, economic, or military action.

The initial use of analogies to understand the outer space environment in the 1960s and 1970s could be taken to indicate a lack of confidence in straightforward descriptions of this new domain of human activity. But their continued prevalence is difficult to understand, given that scientific knowledge of the space environment has improved markedly since the early days of the Space Age. Indeed, it has been claimed that analogies should be used now because they were used in the past. ${ }^{41}$ Reliance on analogies could be accounted for by the fact that very few who discuss space activities and issues will ever actually travel there, but the same can be said for the domains that have been the source of such analogies. The reason analogies are so common is the same reason that they are potentially harmful: an analogy can be used to make a preferred strategy or policy look more suited to the space environment than it really is. The next section reviews some basic misconceptions about the space environment that persist because of reliance on other-domain analogies.

\section{Risks of Analogical Thinking}

The basic attraction of analogies is that they make familiar the otherwise unfamiliar, and are therefore a source of guidance for confronting new situations. They are stronger than metaphors, which simply guide one's orientation, in that analogies suggest that "causal or evaluative beliefs" can be transferred from the familiar to the unfamiliar. ${ }^{42}$ Analogies therefore serve as a vehicle for importing pre-existing legal principles, norms, and rules, but also ideas about what is happening in space, why it is happening, and why that matters. This is an inherently flawed strategy for constructing a political geography, because the material context of the ocean, air, and frozen continent are not the same as the orbital space environment. If specifics of the outer space environment and the nature of outer space activities are very different, why should we expect other sources of international law to work for the space environment? This section seeks to demonstrate how the three main analogies are misleading sources of information about the space environment.

None of these analogies is useful or appropriate for fully defining the political situation in outer space, because each source domain lacks the basic structural features of the target domain. It might be argued that analogies, by definition, contain only partial identity with or similarity to the target domain, and that what they do capture about reality justifies their use. The problem is that analogies are used as an expedient to understand situations without much information, so users are poorly suited to identify which parts of a given analogy are revealing, and which are concealing. Indeed, when analogies are first employed, the user assumes that "the target domain is similar in all respects to the source domain," and use of analogies reduces the incentive to ascertain facts about the target domain - the outer space environment. ${ }^{43}$ This entails a high probability of misreading, misperception, and mistakes in problem definition and interest formation. In other words, analogies provide a poor conceptual foundation for regime building. There are six major features of the orbital space environment that other domain analogies overlook or distort: lack of ecology, lack of fluidity, distribution of access technology, nature of movement, infinite frontier, and existential impacts. 
Unlike the ocean and Antarctica, Earth orbital space and our Solar System seem to contain no ecology - no ecosystems, no endemic life whatsoever. Even if ecosystems are discovered on Mars or the moons of Jupiter or Saturn, they are unlikely to be active, pervasive, and complex, compared to ecosystems on Earth. When this fact is recognized, it is usually used to argue that the outer space environment is especially resilient and there is no one to harm. ${ }^{44} \mathrm{But}$ in many ways the opposite is true, because ecosystems contain properties of self-sustainability and renewal that can moderate and regulate the impacts of human activities. Animals reproduce, carbon can be sequestered, ice refreezes, toxins disperse, and even continental crust is renewed. Outer space does not contain ecological sources of renewal and stabilization; it is fragile and has limited capacity to repair itself. ${ }^{45}$ Space debris cannot be removed the same way the Chesapeake Bay can be cleaned of pollution: there are no filter feeding bivalves in orbit. Lack of ecosystems also means that outer space does not contain harvestable, renewable, resources that can go extinct. The features of these types of resources give unique meaning to 'sustainable use.' Indeed, almost no material resources - finite or renewable - have been harvested from space. The space resources currently used are spatial extension resources, like orbital paths and ballistic missile trajectories. Even these are unlike sea and air lanes, in that their traversal does not entail negative externalities for ecosystems. This creates significantly different conditions for achieving sustainable access and use. It also represents a unique context for treaty negotiations - in the ocean, valuable and readily accessible resources were at stake, whereas in outer space, resources tend to be speculative or difficult to access, especially in the near term. ${ }^{46}$

\section{Lack of Fluidity}

Unlike the ocean and atmosphere, outer space is not a fluid domain in the sense of having 'flows' of liquid or gaseous particles. ${ }^{47}$ Water, air, and vacuum behave very differently. The atmosphere and ocean contain winds and currents - driven by density, heat, and pressure gradients, the Earth's rotation, the gravitational attraction of the Moon, and other material properties - which create patterns of dynamism and circulation within those domains. These dynamic flows shape patterns of ecosystem productivity, distribute external inputs like pollution, and make the borders between such domains fuzzy and fluid. The edges of the atmosphere, ocean, and land are shaped by molecular movements and exchanges in and between each domain, and are constantly in flux due to erosion, deposition, runoff, industrial emissions, and sea surface exchange. The natural borders between each domain are highly porous, and for the purposes of effective international management of environmental problems, they are largely artificial.

In contrast, terrestrial, aerial, and maritime activities barely affect orbital space, and if they do at all, it is through explicit and intentional launches from an earthbound domain to an outer space one. The border with outer space is uncertain, but it is not understood to be undergoing constant fluctuation and exchange like the coastline or sea surface. The only exception to this is when solar flares heat the Earth's outer atmosphere, causing it to temporarily expand. But this dynamism is miniscule and momentary compared to other domains. Because orbital space lacks currents and flows akin to terrestrial domains, the nature of pollution is fundamentally different. In outer space, uncontrolled and 'cast off' objects in tend to spread out evenly in a shell around the Earth. Such pollution, called 'space debris,' does not arrive in orbital space unintentionally, easily, or thoughtlessly, as terrestrial pollution often enters the land, atmosphere, or ocean. 


\section{Distribution of Access Technology}

Space technology, and the way it facilitates access and activity in space, is fundamentally different from aerial and maritime technologies. Take the example of vehicles. 'Ships' are designed for operation in all three non-terrestrial domains, but their common name is more analogy than equivalence. ${ }^{48}$ Aircraft and watercraft - commercial, military, recreational - are durable and reusable. In the case of boats, the technology may be very basic, and is highly diffused across the planet. Although aircraft are more complicated and expensive, they are usually flown for several decades before being decommissioned. In contrast, space access technology is extremely expensive, complex, and fragile. Many space vehicles, such as rockets, are 'single use,' and even reusable space vehicles require significant repair and refurbishment between trips. Although this is not necessarily a permanent condition of space vehicle technology, the difference in operational environments increases the barriers to robust, reusable, and cost effective spacecraft. The material and manufacture of space vehicles is not comparable to aircraft or watercraft; space vehicles can be weaker in some ways, for example because they do not encounter terrestrial weather, but they need to be stronger in others, such as shielding from radiation.

These technological differences are significant, because they result in different numbers, distributions, and types of users. The more distinctive and expensive a technology, the fewer actors have access to it. Distribution factors affect the political conditions for an evolving outer space regime. Depending on the issue at hand, the small number of space users may have vastly more or less leverage. While space actors create precedent and normalize practices, the rest (majority) of the international community can advocate for technology transfer and profit redistribution. Features of space access technology also impact the prospects for regulatory strategies. For example, the question of how and whether to 'flag' a space vehicle via permanent markings was an important part of the negotiations over registration. ${ }^{49}$ Flagging a boat and painting an aircraft proved far easier than marking a vehicle that travels through the atmosphere at extremely high speeds and temperatures. In the early 1970s, the COPUOS Scientific and Technical Subcommittee concluded "there was no feasible way to put marks capable of surviving the high heat of reentry on space objects and their components. ${ }^{" 50}$ Although the outer space regime borrowed the model of flag state jurisdiction from the law of the sea, outer space vehicles could not replicate the practice of physically flagging a ship.

\section{Movement}

In a 2007 article in Astropolitics entitled "On War in Space," Howard Kleinberg argues that the "nature of presence" is different in outer space. ${ }^{51}$ In general, being in space means moving at high speeds. Kleinberg points to the operation of space vehicles, which requires extreme velocities and complex movement in three-dimensions. Vehicles in orbit circumnavigate the entire planet, quickly and from a vantage point. Interactions between space objects are typically done in passing because of the difficulties of syncing up velocities. The space media is unlike other domains because it lacks "surface features, seabeds, or coastal geography to limit motion." Nothing in space itself can be claimed, flagged, or partitioned in a physical, static, and permanent manner. Kleinberg uses these basic insights to reject theories of land-based warfare as applicable to space warfare, but these features of space also demonstrate that space-based operations are generally very different from those on Earth.

\section{Infinite Frontier}


The image of the frontier implies a fundamental similarity between the history of human access to land, atmosphere, ocean, and space. In each planetary domain, humans used advancing technology to access new resources and territorialize new spaces. The vision of outer space as the 'final frontier' implies big payoffs for intrepid explorers, and a way for sovereign states to advance their power and prestige. But the frontier analogy elides the nature of distance in outer space. It implies that the mineral resources on celestial bodies are "accessible, no farther beyond our grasp than the oil beneath the Beaufort" Sea. ${ }^{52}$ Many tantalizing space resources, and especially the prospect of colonies, are out of reach of the physiological limitations of the human body (without major technological innovation). Space travel outside the solar system would exceed the human life span. For humans to survive in outer space, all the basic features of the Earth environment must be recreated and maintained. Although other frontiers, like Antarctica and the deep ocean, were rugged and challenging, those frontiers were a part of the Earth's planetary system and therefore similar or proximate to livable parts of the planet. Those frontiers also have physical edges and ends which are finite and knowable. Outer space is theoretically and practically infinite, a frontier that can never really be crossed.

\section{Existential Impacts}

Outer space contains and entails existential risks for the human species, and possibly all life on Earth. Natural hazards from the land, ocean, and atmosphere - all planetary domains include volcanism, extreme weather, earthquakes, tsunamis, and the disruption of natural systems by human activities. The outer space environment presents a different suite of natural hazards. Outer space itself is extremely dangerous; cosmic radiation is unfiltered by atmosphere, and cosmic debris moves at high speeds. The environmental risk of asteroids and comets extends to the Earth as well. Collision with the Earth represents a low frequency, extremely high magnitude threat to human survival unparalleled in the other planetary domains.

Table 1. Analogies for Outer Space.

\begin{tabular}{|l|l|l|l|l|}
\hline Analogy & Version & What it captures & What it misses & Presence in regime \\
\hline Ocean & High seas & $\begin{array}{l}\text { Vast, fluid; } \\
\text { Solid islands; } \\
\text { Obstacles to deep access; } \\
\text { Coastal area (airspace) }\end{array}$ & $\begin{array}{l}\text { Infinite; } \\
\text { Effective distance (speed of } \\
\text { vehicles); } \\
\text { Delicate and expensive } \\
\text { technology; } \\
\text { Security issues; } \\
\text { Space ports (leave, don't } \\
\text { arrive) }\end{array}$ & $\begin{array}{l}\text { National registration; } \\
\text { International commons; } \\
\text { CIL principles instead of } \\
\text { positive rules; } \\
\text { Rescue obligations }\end{array}$ \\
\hline Ocean/Land & Seabed & $\begin{array}{l}\text { Vast potential mineral } \\
\text { wealth; } \\
\text { Obstacles to access }\end{array}$ & $\begin{array}{l}\text { Infinite; } \\
\text { No ecological context; } \\
\text { Separate mineral caches; } \\
\text { Abundance of helium }\end{array}$ & Moon Treaty (CHM) \\
\hline Land & Antarctica & $\begin{array}{l}\text { Harsh environment; } \\
\text { Fragile environment; } \\
\text { unknown resource extent; } \\
\text { Distance; } \\
\text { Uninhabited except for few } \\
\text { settlements }\end{array}$ & $\begin{array}{l}\text { Infinite; } \\
\text { Mostly unable to partition; } \\
\text { Requirement of advanced } \\
\text { technology }\end{array}$ & $\begin{array}{l}\text { International commons; } \\
\text { National control over } \\
\text { humans, vehicles, stations; } \\
\text { functional coordination } \\
\text { comes first; scientific } \\
\text { cooperation }\end{array}$ \\
\hline Atmosphere & Airspace & $\begin{array}{l}\text { Ascendance and 'flying'; } \\
\text { Vehicle safety issues; } \\
\text { Vehicle registration needs }\end{array}$ & $\begin{array}{l}\text { Infinite; } \\
\text { Orbital mechanics; } \\
\text { Obstacles to partition }\end{array}$ & Liability rules \\
\hline
\end{tabular}


Analogies between the outer space environment and Earth's land, ocean, or atmosphere are misleading. Because planetary and extra-planetary domains are fundamentally different from one other, it is not likely that regime features designed to govern one domain will be effective when applied to another. The distinctive features of the ocean, atmosphere, Antarctica, and outer space entail different constraints, opportunities, and motivations for regime building. ${ }^{53}$ The actors with influence and stakes are different, as are the consequences of poor governance. Analogies are therefore unlikely to inform durable and effective solutions to collective problems in outer space, because they import rules, norms, and principles from regimes designed for fundamentally different places. Spatial disorientation makes for difficult steering.

\section{Outer Space as a Place}

Analogies are intended to make new situations or things familiar and understandable, but eventually they can be replaced with direct information about their target. The processes of scientific knowledge production and technological advancement have continued for decades after the construction of the outer space regime; our abilities in and understandings of the space environment are significantly advanced relative to the 1960s. Analogies are no longer necessary to provide a 'locational classification' for outer space. Scientific and technical experts generally comprehend the basic physical features and patterns of the outer space environment. The image of outer space described in this section reflects the basic features of their consensus.

Gravity is the dominant force shaping the material context in outer space, and especially the areas surrounding celestial objects. Gravity shapes the outer space environment near Earth in two major ways: by creating pathways for continuous high velocity travel around the planet, and by making travel into space very energetically burdensome. Earth orbital space - the part of space where the Earth's gravitational attraction is overwhelmingly dominant - is better understood as the outer layer of the planet, as opposed to the nearest areas of the infinite universe. Virtually everything humans have done in space has occurred in the so-called 'gravity well,' a conceptual metaphor that describes the fact that gravitational attraction falls off in a nonlinear relationship to distance. This feature of gravity means that the bulk of the energy required to get somewhere in space is expended in the early stages of escaping Earth's gravitational pull.

Although orbital space is vastly larger than the atmosphere in total volume, the increase in speed made possible because of lack of friction means that distance is compressed. Outer space travel represents a decrease in "effective distance": even very long distances can be traversed quickly when traveling at very high speeds ${ }^{54}$. This speed of travel makes space attractive for military and potentially commercial users. But high speeds are not just required in space, they are necessary for most space activities. The supposed cornucopia of space resources and habitats are scattered at huge distances from the Earth. Achieving a stable orbit requires reaching orbital velocity, which depends on the mass of the object to be orbited. Orbital velocity for the Earth is at least 17,500 miles per hour. At this velocity, an object can circumnavigate the planet in about 90 minutes. There are several different types of orbit, or paths that a satellite can take in its revolutions around the Earth. Orbital paths have three features: height, eccentricity (near-circular or elliptical), and inclination (angle relative to equator). The choice of orbit depends on the use of the satellite. Because satellites sit outside Earth's atmosphere and above the terrestrial environment, they have positional advantages that makes them attractive for many different uses. 
The environment of outer space is overwhelmingly inhospitable to human life, and creates a set of obstacles for the operation and maintenance of human technology. Outer space is difficult to get to, be in, and return from. Because it is a vacuum, terrestrial organisms cannot live in outer space without the assistance of advanced technology. Space-based objects experience enormous variation in temperature, depending on their location relative to the Sun. Outside of the protective filter of the atmosphere, radiation abounds. The 'solar wind' entails a continuous and high-velocity flow of charged particles from the sun, with occasional eruptions of intense high-energy radiation called 'solar flares.' An additional source of radiation is 'cosmic rays' from outside the solar system. These high-energy particles travel an appreciable fraction of the speed of light, and can do massive damage to biological tissue. Such radiation flows through orbital space, but it is also concentrated there. The Van Allen belts are dense layers of charged particles held around the Earth by its magnetic field, which can also do damage to humans and human technology. This environment makes human spaceflight very difficult biologically, and requires that everything done in space (with or without humans) include elaborate shielding. We must do artificially what the atmosphere does naturally. This vastly increases the cost of doing things in space, and has encouraged a shift from human to robot-based activity.

Space vehicle technology faces three major tasks: escaping gravity to reach orbital space, maintaining structural integrity while there, and in some cases, safely returning to Earth through the atmosphere. Each step entails significant design and materials requirements for space vehicles. Launching requires powerful rockets and large amounts of fuel, and high launch costs have persisted throughout the Space Age and obstructed the diffusion of access to space. The approximate cost of putting a pound in orbit is $\$ 10,000$, and roughly 85 percent of a rocket's weight at the launch pad is fuel. ${ }^{55}$ Because the pull of gravity is consistent, reducing launch costs can only be achieved by decreasing the weight of payloads to minimize the amount of fuel required, or through reusable vehicles. Operations in orbit require fuel and situational awareness, to maintain orbits and to avoid dangerous space debris. Re-entry seems like the easy part, because vehicles are moving in the direction gravity pulls them. But moving from frictionless space into a friction-filled atmosphere is arduous, because friction causes a great increase in temperature. Indeed, space vehicles become sheathed in plasma for part of re-entry. This requires materials that can withstand extreme heat and pressure.

Celestial bodies are a large physical outer space resource. In addition to the planets that orbit our Sun and other stars, and the moons that orbit those planets, asteroids populate the space environment. Humans have only known about asteroids for around 200 years, and initially they were a curiosity for astronomers. In the past three decades, however, scientists have increasingly catalogued 'near Earth objects' (asteroids and comets) that may present a risk of collision with the Earth. In these same decades, scientists first learned "the basic physical properties of asteroids, such as rotation rate, size, shape, composition, and origin." ${ }^{56}$ This knowledge - made possible by innovations in electronics and computing - supported the conceptualization of asteroids as a resource to be mined by humans. ${ }^{57}$ In comparison to other celestial bodies, asteroids are relatively accessible, have negligible gravity, and are therefore easy to move and easy to leave. Many of them are known to contain valuable minerals, and comets may contain useful materials like water, methane, and ammonia.

This brief sketch of a non-analogical representation of outer space illustrates a variety of conditions that shape outer space activities. The space environment creates durable and predictable material trends regarding launch requirements, orbital paths, human physiological limitations, remote sensing and communication physics, and other features of space activity. The 
space environment contains valuable resources, with spatial extension resources (like orbital position) closer to Earth and harvestable resources (like minerals) scattered across huge distances. The movement of celestial bodies like asteroids represents an opportunity, by making mineral resources more accessible, and a threat, because they periodically collide with the Earth. Movement is the norm for objects in space, and most uncontrolled objects do not slow or accumulate, but instead are spread and multiplied by orbital dynamics. These features of outer space activity are immune to shifts in interests or distribution of power among states. They affect the motivations for and requirements of space access, including what resources space technologies are designed to pursue, and the features and cost of those technologies. The outer space material context also determines what kinds of threats exist (who they threaten and how), including space weapons, space debris, and asteroid collision. These features of the space environment ought to set the agenda of regime formation for outer space, but when analogies are used, they can be downplayed or overlooked.

There are several general conclusions from the constraints and opportunities of the space material context described above. First, the nature of space access makes the public-private relationship something different than that envisioned by early regime builders. Major states were concerned about sovereign appropriation of outer space in the 1960s and 1970s, but gave little thought to the potential of uncontrolled private actors in space. The regime reflects as much: although it explicitly rules out national territorial claims, many argue that it allows for privatization of harvested resources. Indeed, there is an "almost comprehensive absence of substantive provisions specifically circumscribing private space activities," so the regime is essentially permissive. ${ }^{58}$ Private actors have wide latitude in their choice of registry, and the state of registry assumes ultimate liability if anything goes wrong. The shift to private space actors relates to the material context of outer space. Access technology is advanced and expensive, but has remained generally the same for decades. Launch and orbit is therefore accessible to anyone with enough money. And because mineral resources are high risk and high reward, entrepreneurs are more likely and able to pursue the massive speculative investments required, compared to states with ample domestic responsibilities. The activities and claims of private commercial actors are enabled by the current regime, and likely to cause new conflict in outer space governance. The flag state model that governs the public-private relationship in space was borrowed from the law of the sea.

Second, space objects cannot be outlawed based on their potential for harm; anything can be a space weapon. This situation results from the fragile nature of satellites, their easy-to-target ascendant position, and the high velocities of orbital operation. The OST prohibits weapons of mass destruction in orbit, and attempts to outlaw space weapons generally by requiring that 'space activities' and 'space objects' must be for peaceful purposes. But the majority of space technology is 'dual use,' meaning that it is difficult to distinguish objects based on their potential for peaceful or aggressive use. ${ }^{59}$ Any object in space can damage a satellite or space vehicle by running into it, and it would be very difficult to distinguish an accidental collision from an intentional one. There is a problem of discrimination, where a test or targeted use may indiscriminately harm non-target users. There is also a problem of attribution, because the prevalence of ambient and dangerous space debris increases the risk of unintentional damage, which may be misperceived as intentional and planned. Anything in space can be used as a weapon, and it can be difficult to tell whether it was a weapon even after the damage occurs. This distinctiveness issue does not exist in the ocean, atmosphere, or Antarctica, and is overlooked or ignored by the OST regime. 
Third, the orbital environment is subject to rapid degradation. The construction of the OST regime occurred during a period of ignorance about the geophysical-technological interaction that creates the space debris problem. NASA scientists recognized the hazard of natural space debris in the early 1960s, but anthropogenic debris was not an object of focused research until the mid-1970s. ${ }^{60}$ The problem of multiplying orbital space debris was first described by NASA scientists Donald Kessler and Burton Cour-Palais in their 1978 paper "Collision Frequency of Artificial Satellites: The Creation of a Debris Belt." The phenomenon of 'breeding' or multiplying debris became known as the "Kessler Syndrome." According to Kessler himself, "nobody believed it initially." ${ }_{61}$ The idea of risk and limitation in orbital space contradicted the prevailing view that space was a "limitless environment" and a "virtually infinite sink for pollution." 62 At the time of regime formation, the high seas analogy did not invite consideration of the risk of environmental pollution. During this period, the ocean was conceived as a "great neutralizer, with virtually unlimited ability to absorb noxious substances."63 But even if pollution had been a salient feature of analogies at the time, space debris is a qualitatively different type of pollution problem because of its origins, how it spreads, and the limited and extremely slow means by which it is naturally removed through orbital decay.

Finally, the problem of catastrophic and existential risks from asteroid collision is neither acknowledged nor addressed by the outer space regime. None of the domain analogies drawn upon during its formation capture the magnitude of this threat. Collision is now generally understood to be inevitable, but this realization emerged after the core elements of the OST regime were negotiated. Astronomers in the 1980s began to realize that near Earth objects were numerous, and many came "uncomfortably close to Earth." 64 . Humanity has a clear, definite collective interest in preparing for the detection and diversion of collision scenarios: "An asteroid or comet is the only natural disaster that can wipe out human society and the only natural disaster that human society can prevent." ${ }^{65}$ And because the development and deployment of deflection techniques requires a long lead-time, starting now is imperative to avoid the risk of asteroid collision. ${ }^{66}$ Continued reliance on analogies will not effectively account for this threat. Even if it were compared with Earth-based or anthropogenic catastrophe scenarios, the risk of asteroid collision has an essential and unique feature: unlike most natural disasters, "cosmic hazards are unusual in that they are not spatially selective... any point on the planet appears to have a similar chance of being struck." 67 This randomness makes the threat seem diffuse, when it is actually very acute in the places that are struck, with reverberating consequences that damage surrounding regions. This situation creates a special need and challenge for regime building, one that could be overlooked when relying on other domain analogies.

\section{Conclusion}

The central argument of this article is that using direct scientific evidence to construct a representation of the outer space environment is superior to relying on analogical comparisons with various planetary domains. Specifically, using an image of space that does not depend on analogy is a better 'locational classification' on which to base the international law of outer space. Because a representation from direct evidence takes longer to piece together - to collect data and construct and test theories - resisting reliance on analogies may have the effect of discouraging hasty conclusions about what is and will happen in space, and what needs to be done. And when rules are made and practices normalized, they may better reflect a sober and informed understanding about consequences for the space environment. Because domain 
analogies historically shifted with interest and power, members of the international community built the outer space regime that seemed most advantageous to their state or bloc, as opposed to the regime that best matched the material context of outer space. Although that 'ship has sailed' historically, the argument outlined here ought to inform additional regime building for space. Scholars of different types of space activity may draw different conclusions about the implications of outer space as a place for policymaking, international law, and grand strategy. But the conclusions they draw about 'what we should do' will be better for achieving collective goals, and avoiding shared vulnerabilities, if they are based on a realistic and scientific representation of outer space as a place.

Notes

${ }^{1}$ M. J. Peterson, International Regimes for the Final Frontier, SUNY Series in Global Politics (Albany: State University of New York Press, 2005), 67.

${ }^{2}$ Peterson, International Regimes for the Final Frontier; Sven Grahn, "Why We Had Better Drop Analogies When Discussing the Role of Humans in Space," in Humans in Outer Space - Interdisciplinary Odysseys, ed. Luca Codignola and Kai-Uwe Schrogl, vol. 1 (Vienna: Springer Vienna, 2009); Howard E. McCurdy, "Reaching for Higher Altitudes: Mountaineering Analogies and the Commercialization of Outer Space," Astropolitics 12, no. 2-3 (September 2, 2014): 132-47.

${ }^{3}$ M.J. Peterson, "The Use of Analogies in Developing Outer Space Law," International Organization 51, no. 2 (Spring 1997): 245-74.

${ }^{4}$ Peterson, 250, 269.

5 Jason Beery, "Unearthing Global Natures: Outer Space and Scalar Politics," Political Geography 55 (November 2016): 92-101.

${ }^{6}$ Beery, 94.

${ }^{7}$ R. D. Launius, "Writing the History of Space's Extreme Environment," Environmental History 15, no. 3 (July 1, 2010): 526-32.

${ }^{8}$ Glenn H. Reynolds and Robert P. Merges, Outer Space: Problems of Law and Policy, 2. ed (Boulder, Colo.:

Westview Pr, 1998), 47.

${ }^{9}$ Peterson, International Regimes for the Final Frontier, 13.

10 Peterson, 7.

11 Andrew Brearly, "Mining the Moon: Owning the Night Sky?," Astropolitics 4, no. 1 (2006): 48.

${ }^{12}$ Irvin L. White, Decision-Making for Space: Law and Politics in Air, Sea, and Outer Space (Purdue University Studies, 1970).

${ }^{13}$ Peterson, "The Use of Analogies in Developing Outer Space Law," 268.

${ }^{14}$ Peterson, 252.

${ }^{15}$ William E Burrows, This New Ocean: The Story of the First Space Age (Modern Library, 2010).

${ }^{16}$ Peterson, "The Use of Analogies in Developing Outer Space Law," 252.

${ }^{17}$ Philip C. Jessup and Howard J. Taubenfeld, Controls for Outer Space and the Antarctic Analogy (New York: Columbia University Press, 1959), 212.

${ }^{18}$ Dandridge M. Cole and Donald W. Cox, Islands in Space: The Challenge of the Planetoids (Philadelphia, PA: Chilton Company, 1964), 7-8.

${ }^{19}$ Peterson, "The Use of Analogies in Developing Outer Space Law," 258.

${ }^{20}$ James Spiller, "Scientific Exploration in Antarctica as an Analogy for American Spaceflight," Astropolitics 12 , no. 2-3 (September 2, 2014): 182.

${ }^{21}$ Spiller, 185.

22 Spiller, 184.

23 Spiller, 181.

${ }^{24}$ Jessup and Taubenfeld, Controls for Outer Space and the Antarctic Analogy, 6.

${ }^{25}$ Everett C. Dolman, Astropolitik: Classical Geopolitics in the Space Age, Cass Series--Strategy and History (London ; Portland, OR: Frank Cass, 2002), 123.

${ }^{26}$ Peterson, "The Use of Analogies in Developing Outer Space Law," 257-59.

${ }^{27}$ Spiller, "Scientific Exploration in Antarctica as an Analogy for American Spaceflight," 181. 
${ }^{28}$ Spiller, 186.

${ }^{29}$ Spiller, $188-89$.

${ }^{30}$ Spiller, 190.

${ }^{31}$ Astropolitics Volume 12 Issue 2-3, 2014

${ }^{32}$ Roger D. Launius, "Power of Analogies for Advancing Space Scientific Knowledge," Astropolitics 12, no. 2-3 (September 2, 2014): 130-31.

${ }^{33}$ McCurdy, "Reaching for Higher Altitudes"; Launius, "Power of Analogies for Advancing Space Scientific Knowledge."

${ }^{34}$ Catherine L. Newell, "Without Having Seen: Faith, the Future, and the Final American Frontier," Astropolitics 12, no. 2-3 (September 2, 2014): 148-66; Spiller, "Scientific Exploration in Antarctica as an Analogy for American Spaceflight."

${ }^{35}$ Lisa Messeri, "Earth as Analog: The Disciplinary Debate and Astronaut Training That Took Geology to the Moon," Astropolitics 12, no. 2-3 (September 2, 2014): 196-209; Steven J. Dick, "Analogy and the Societal Implications of Astrobiology," Astropolitics 12, no. 2-3 (September 2, 2014): 210-30.

${ }^{36}$ Larry M. Wortzel, "The Chinese People's Liberation Army and Space Warfare," Astropolitics 6, no. 2 (2008): 112-37; Jeremy Straub, "Application of a Maritime Framework to Space: Deep Space Conflict and Warfare Scenario," Astropolitics 13, no. 1 (January 2, 2015): 65-77; Thomas Cremins and Paul D. Spudis, "Viewpoint: The Strategic Context of the Moon Echoes of the Past, Symphony of the Future," Astropolitics 5, no. 1 (August 2007): 87-104; Alan Steinberg, "Weapons in Space: The Need to Protect Space Assets," Astropolitics 10, no. 3 (December 2012): 248-67.

${ }^{37}$ Scott Pace, "Space Cooperation among Order-Building Powers," Space Policy 36 (May 2016): 24-27; Steinberg, "Weapons in Space"; Wortzel, "The Chinese People's Liberation Army and Space Warfare"; Straub, "Application of a Maritime Framework to Space"; Jon Sumida, "Old Thoughts, New Problems: Mahan and the Consideration of Seapower," in Toward a Theory of Spacepower, ed. Charles D. Lutes and Peter L. Hays (National Defense University: Institute for National Strategic Studies, 2011), 10; Colonel John E. Shaw, "Guarding the High Ocean: Towards a New National Security Space Strategy Through an Analysis of US Maritime Strategy," Air \& Space Power Journal, Spring 2009, 2.

${ }^{38}$ Jesse Dunietz, "Floating Treasure: Space Law Needs to Catch Up with Asteroid Mining," Scientific American, August 28, 2017; Brearly, "Mining the Moon: Owning the Night Sky?"; Ian B. Perry, "Law of Space Resources and Operations on Celestial Bodies: Implications for Legislation in the United States," Astropolitics 15, no. 1 (January 2, 2017): 1-26; Frans G. von der Dunk, "Sovereignty Versus Space - Publc Law and Private Launch in the Asian Context," Singapore Journal of International \& Comparative Law 5 (2001): 22-47.

${ }^{39}$ Spiller, "Scientific Exploration in Antarctica as an Analogy for American Spaceflight," 193.

${ }^{40}$ Brearly, "Mining the Moon: Owning the Night Sky?," 49.

${ }^{41}$ Brearly, 48.

${ }^{42}$ Peterson, International Regimes for the Final Frontier, 7.

${ }^{43}$ Peterson, 7.

${ }^{44}$ David Brin, "The Arguments against Space Exploration," in Beyond Spaceship Earth: Environmental Ethics and the Solar System, ed. Eugene C. Hargrove (San Francisco: Sierra Club Books, 1986), 14.

${ }^{45}$ James Clay Moltz, The Politics of Space Security: Strategic Restraint and the Pursuit of National Interests (Stanford, Calif: Stanford Security Studies, 2008), 6.

${ }^{46}$ Ann L Hollick, U.S. Foreign Policy and the Law of the Sea (Princeton, N.J.: Princeton University Press, 1981), 14.

${ }^{47}$ The phenomenon of 'solar wind' is not comparable, despite its name. Solar winds do not constitute (or fill) the outer space environment the ways that air and water molecules constitute the atmosphere and ocean. Solar wind flows outward from the sun, instead of circulating, and it is made of plasma, and therefore not a medium that can be inhabited or traversed.

${ }^{48}$ The first three entries for 'ship' in the New Oxford American Dictionary refer to racing boats, sailing vessels, and transportation by the sea. The fourth entry is for a 'spaceship' and the last for an aircraft, with the qualification that this last meaning is common only in North America.

${ }^{49}$ Peterson, International Regimes for the Final Frontier, 88.

${ }^{50}$ Peterson, 98.

${ }^{51}$ Howard Kleinberg, "On War in Space,” Astropolitics 5, no. 1 (August 2007): 1-27.

${ }_{52}^{52}$ Brin, "The Arguments against Space Exploration," 14.

${ }^{53}$ Susan J Buck, The Global Commons an Introduction (Washington, D.C.: Island Press, 1998), 10. 
${ }^{54}$ Daniel Deudney, Dark Skies: Space Expansionism, Planetary Geopolitics and the Ends of Humanity (Oxford University Press, 2018).

${ }^{55}$ Don Pettit, "The Tyranny of the Rocket Equation," National Aeronautics and Space Administration, Expedition 30 (blog), May 1, 2012; Sarah Kramer and Dave Mosher, "Here's How Much Money It Actually Costs to Launch Stuff into Space," Business Insider, July 20, 2016.

${ }^{56}$ Curtis Peebles, Asteroids: A History (Smithsonian, 2016), 239.

${ }^{57}$ John S. Lewis, Mining the Sky: Untold Riches from the Asteroids, Comets, and Planets (Perseus Books, 1996).

${ }^{58}$ Frans G. von der Dunk, "Sovereignty Versus Space - Publc Law and Private Launch in the Asian Context," Singapore Journal of International \& Comparative Law 5 (2001): 46.

${ }^{59}$ Klaus Dodds, "Introduction - The Governance of the Global Commons: Much Unfinished Business?: The Governance of the Global Commons," Global Policy 3, no. 1 (February 2012): 59.

${ }^{60}$ Elmer H. Davison and Paul C. Winslow, "Space Debris Hazard Evaluation," Technical Report (Cleveland, OH: NASA Lewis Research Center, December 1, 1961); T.D. Bess, "Mass Distribution of Orbiting Man-Made Space Debris," Technical Report (Langley Station, VA: NASA Langley Research Center, December 1975); D.R. Brooks, "A Comparison of Spacecraft Penetration Hazards Due to Meteoroids and Manmade Earth-Orbiting Objects," Technical Report (Langley Station, VA: NASA Langley Research Center, November 1976).

${ }^{61}$ Gregory Mone, "Donald Kessler: Prophet of Space Trash.," Discover 32, no. 10 (December 2011): 15.

${ }^{62}$ Mone.

${ }^{63}$ Jacob Darwin Hamblin, Arming Mother Nature: The Birth of Catastrophic Environmentalism (Oxford: Oxford Univ. Press, 2013), 99.

${ }^{64}$ M. J. Peterson, International Regimes for the Final Frontier, SUNY Series in Global Politics (Albany: State University of New York Press, 2005), 87.

${ }^{65}$ Harold D. Foster, "Disaster Planning for Cosmic Impacts: Progress and Weaknesses," in Comet/Asteroid Impacts and Human Society: An Interdisciplinary Approach, ed. Peter T. Bobrowsky and H. Rickman, 1st ed (Berlin ; New York: Springer, 2007), 455.

${ }^{66}$ Peebles, Asteroids: A History, 236.

${ }^{67}$ Joseph Packer, Jessica A. Kurr, and Adam Abelkop, “The Policy Trajectory of United States Asteroid Deflection Planning," Timely Interventions: A Translational Journal of Public Policy Debate 1, no. 1 (2013): 7. 